\title{
Baseline Nausea and Vomiting Scale
}

National Cancer Institute

\section{Source}

National Cancer Institute. Baseline Nausea and Vomiting Scale. NCI Thesaurus. Code C147033.

A scale for the subjective scoring of nausea that ranges from 0: No nausea at all to 10 : Nausea as bad as it can be. 